\title{
A METHOD FOR ANALYZING THE INFLUENCE OF PROCESS AND DESIGN PARAMETERS ON THE BUILD TIME OF ADDITIVELY MANUFACTURED COMPONENTS
}

\author{
Hallmann, Martin; Schleich, Benjamin; Wartzack, Sandro \\ Friedrich-Alexander-Universität Erlangen-Nürnberg
}

\begin{abstract}
When using additive manufacturing processes, the choice of the numerous settings for the process and design parameters significantly influences the build and production time. To reduce the required build time, it is useful to adapt the parameters with the greatest influence. However, since the contribution of the individual parameters is not readily apparent, a sensible choice of process and design parameters can become a challenging task.

Thus, the following article presents a method, that enables the product developer to determine the main contributors to the required build time of additively manufactured products. By using this sensitivity analysis method, the contributors of the individual parameters can be analyzed for a given parametrized CAD model with the help of an analysis-based build time estimation approach. The novelty of the contribution can be found in providing a method that allows studying both design and process parameters simultaneously, taking the machine to be used into account. The exemplary application of the presented method to a sample part manufactured by Fused Deposition Modeling demonstrates its benefits and applicability.
\end{abstract}

Keywords: Additive Manufacturing, 3D printing, Design for Additive Manufacturing (DfAM), Sensitivity analysis, Analysis-based build time estimation

Contact:

Hallmann, Martin

Friedrich-Alexander-Universität Erlangen-Nürnberg

Engineering Design

Germany

hallmann@mfk.fau.de

Cite this article: Hallmann, M., Schleich, B., Wartzack, S. (2019) 'A Method for Analyzing the Influence of Process and Design Parameters on the Build Time of Additively Manufactured Components', in Proceedings of the 22nd International Conference on Engineering Design (ICED19), Delft, The Netherlands, 5-8 August 2019. DOI:10.1017/dsi.2019.69 


\section{INTRODUCTION}

In recent decades, the performance of additive manufacturing processes has continuously increased, so that they are used in various industrial sectors in the context of Rapid Prototyping, Rapid Tooling and Rapid Manufacturing today (Wohlers and Campbell, 2017). The different new manufacturing processes could impressively prove their industrial maturity in recent years, not least because of their numerous advantages such as low production costs and great freedom of design (Mohamed et al., 2015). Even low-cost printers can nowadays achieve very good results with only a few minor constructive adaptions (Hallmann et al., 2018a) although the accuracy of additively manufactured parts is still lower than that of traditionally manufactured ones (Hallmann et al., 2018b). Apart from product quality, mechanical properties and acceptable costs of production systems, short build times are one of the most important factors for the successful usage of additive manufacturing processes in industry (Rao and Rai, 2016). However, there is a huge number of influences on the build time (Han et al., 2003) and their contribution strongly depends on the product design which is defined by the product designer. This makes it very difficult for especially less experienced product developers to estimate the main influence factors from both design and manufacturing. The product developer often does not have a sufficiently deep manufacturing knowledge to identify the non-obvious, product-specific interrelations. This leads to the question how the product developer can be supported to do first evaluations of the contribution of part build orientation, process parameters and design parameters to the build time.

Motivated by this research gap, the following article presents a novel method for analyzing the influence of the design and process parameters on the build time using the CAD model of the part to be manufactured. By coupling the method of sensitivity analysis with the software for process preparation, the analysis-based build time estimation is based on the machine code used for production. The results of the sensitivity analysis indicate the contribution of the individual variables to the build time and can be used to identify the most relevant parameters, which are useful for design reviews and subsequent manual or automatic optimization processes.

The paper is structured as follows: After presenting the state of the art in section 1, the developed method is described in detail in section 2. The basic idea and the general framework of the method is illustrated in section 2.1, the structure of the method with its main modules and its implementation is discussed in detail in section 2.2 and section 2.3. Afterwards, the proposed method is exemplarily applied to a case study in section 3 to show the benefits of the method and to derive initial findings. Finally, a conclusion and a brief outlook is given in section 4 .

\section{STATE OF THE ART}

As a successful product must meet the requirements of a wide variety of interest groups, the product development process is dominated by conflicts of interests and objectives. Therefore, it is the task of the product developer to take the fulfillment of the various objectives into account when designing a product. These objectives often compete with each other, so that the achievement of one objective means that other ones cannot or only partly be achieved (Luft et al., 2016).

For a prosperous application of additive manufacturing processes, a simultaneous consideration of objectives is indispensable (Ziemian and Crawn III, 2002; Rao and Rai, 2016). Thus, the numerous objectives either define the performance, e.g. build time or material effort, or the efficiency, e.g. mechanical and tribological properties as well as surface roughness and geometric accuracy. (Ziemian and Crawn III, 2002; Griffiths et al., 2016). The production costs are essentially determined by the required amount and quality of material and build time. Especially the latter, which can last from several hours up to day(s) depending on the model complexity (Han et al., 2003), arouse special interest in industry (Durgun and Ertan, 2014).

The choice of the process parameters, the part build orientation and the geometry mainly influence the build time and thus the time required for the entire manufacturing process, which is directly linked to the manufacturing costs (Kechagias et al., 1997; Ingole et al., 2011). Thus, a large part of the research activities focuses on the various parameters. Table 1 summarizes the studied parameters with its references.

For a reliable prediction of the build time depending on these various influence parameters, appropriate information is essential. Therefore, several computer-aided approaches for build time estimation or rather prediction are developed delivering an accurate build time and cost estimation, which takes all the 
process parameters, influencing the machine movement, into account. These methods are divided into two main groups: detailed analysis- and parametric-based build time estimators. Detailed analysisbased build time estimators predict the total build time by analyzing the individual activities in the manufacturing process for a given part design. Due to their mode of operation, these estimation techniques are used in combination with a preprocessing software to slice the geometry and to generate the toolpaths by considering the selected manufacturing process and machine. (Di Angelo and Di Stefano, 2011) In contrast, parametric-based procedures try to establish more generally valid approaches using traditional and advanced techniques, e.g. artificial neural networks (Munguía et al., 2009; Di Angelo and Di Stefano, 2011), taking theoretical and experimental background into account. Both methods are developed for the most common additive manufacturing processes such as Laminated Object Manufacturing (Kechagias et al., 1997), Material Jetting (Baumers et al., 2015), Selective Laser Sintering (Choi and Samavedam, 2002), Stereolithography (Frank and Fadel, 1995; Chen and Sullivan, 1996) and Fused Deposition Modeling (FDM) (Zhu et al., 2016; Komineas et al., 2018). As a consequence, the scientific efforts of recent years improved the computer-based methods for build time estimation delivering a very good agreement of estimated and real build time (Komineas et al., 2018).

These techniques are frequently used in the product development process to analyze the influences of these parameters and to determine an optimal choice of them (Mohamed et al., 2015; Rao and Rai, 2016). For the analysis of the effect of individual parameters, the TAGUCHI method (Nancharaiah, 2011; Ali et al., 2014) and the analysis of variance (ANOVA) (Kumar and Regalla, 2011; Nancharaiah, 2011) are frequently used. The results can for example serve as a basis for deriving design guidelines (Srivastava et al., 2015; Pradel et al., 2018), setting up expert systems (Frank and Fadel, 1995) or identifying the relevant design parameters for subsequent single- (Thrimurthulu et al., 2004; Rayegani and Onwubolu, 2014) or multi-objective optimization (Sanati-Nezhad et al., 2009; Rao and Rai, 2016) procedures.

However, these methods either require an adaptation of mathematical models for build time estimation or are limited to a small number of selected parameters. A simultaneous consideration of part build orientation, process and design parameters is missing, although the main contributors strongly depend on the part geometry and the used additive manufacturing machine. Tis information is certainly an important basis for the communication between product design and manufacturing to ensure the efficiency of additive manufacturing processes. At the current state of the art, it is unclear how the product developer can suitably be supported by simultaneously analyzing the influences on the build time from both the production and product design point of view. To answer this research question, this paper presents a novel method for build time sensitivity analysis on the basis of the CAD model. The integration of a CAD software and preprocessing software into the build time sensitivity analysis approach enables the simultaneous study of design parameters, process parameters and part build orientation. This increases the applicability of the method throughout the product development process.

Table 1. Influence parameters on build time studied in literature

\begin{tabular}{l|l} 
Studied parameter & References \\
\hline $\begin{array}{l}\text { Part build orientation } \\
\text { Process parameters }\end{array}$ & (Thrimurthulu et al., 2004; Sanati-Nezhad et al., 2009; Ingole et al., 2011) \\
$\begin{array}{l}\text { layer thickness } \\
\text { extrusion, filling velocity }\end{array}$ & (Kumar and Regalla, 2011; Peng et al., 2014; Rao and Rai, 2016; Srivastava et al., 2015) \\
contour width & (Kumar and Regalla, 2011; Srivastava et al., 2015) \\
raster air gap & (Nancharaiah, 2011; Ali et al., 2014; Srivastava et al., 2015; Rao and Rai, 2016) \\
raster width & (Kumar and Regalla, 2011; Mendonsa et al., 2015; Rao and Rai, 2016) \\
raster angle & (Nancharaiah, 2011; Ali et al., 2014; Rao and Rai, 2016) \\
Part geometry & (Pradel et al., 2018) \\
Design for assembly & (Oh and Behdad, 2016)
\end{tabular}




\section{INFLUENCE OF PART BUILD ORIENTATION, DESIGN AND PROCESS PARAMETERS ON THE BUILD TIME OF ADDITIVE MANUFACTURING PROCESSES}

In order to overcome the lack of suitable methods for build time sensitivity analysis discussed in section 1, a novel method is presented in the following. By combining the method of sensitivity analysis with a CAD software and preprocessing software for the additive manufacturing, the sensitivity analysis is fully automated and can be applied to any application. While section 2.1 shows the basic idea and the general framework, section 2.2 describes the main components in detail. Its implementation is shown in section 2.3

\subsection{Basic idea and general framework}

It is known from section 1 that the choice of the process parameters, the part build orientation and the design of the product have a strong influence on the build time (Kechagias et al., 1997). Thus, all of the parameters to be studied with their technically feasible definition ranges are used as input variables for the automatic sensitivity analysis (see Figure 1). In order to estimate the sensitivities, a suitable design of experiment is required to consider the possible variations of all parameters within their definition range. For all the different configurations, the required build time is predicted using a detailed analysis-based build time estimation technique. This information is used to estimate their contributions to the build time. The result is a ranking of the contributors of the individual parameters. Depending on the implementation of the respective build time estimator, deviations of the estimated and the real manufacturing time may occur. However, they are mostly very small and, if at all, they have no significant influence on the results of the sensitivity analysis, especially since the results serve as a qualitative discussion and decision basis.

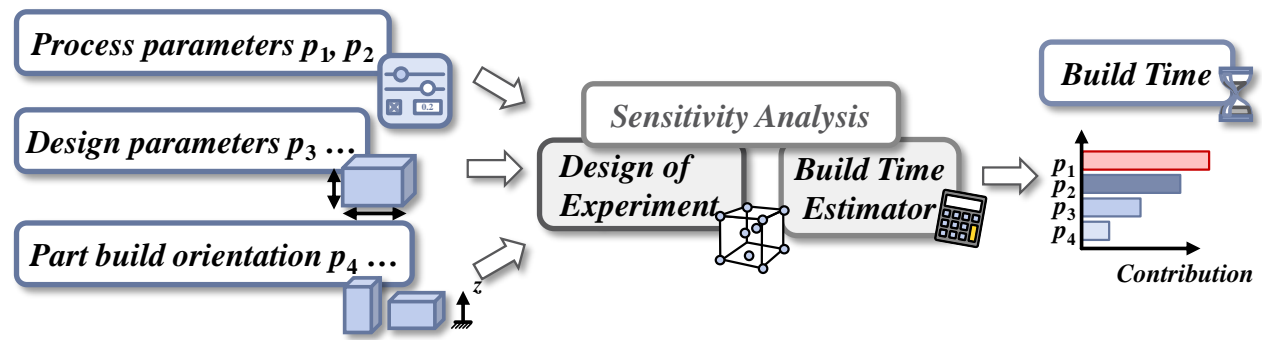

Figure 1. General framework of build time sensitivity analysis for the additive manufacturing

\subsection{Build time sensitivity analysis using detailed analysis-based build time estimators}

Since the fundamental idea is known from section 2.1, the detailed method is examined in the following. Figure 2 illustrates the workflow of the proposed method for build time sensitivity analysis in detail based on the basic idea illustrated in Figure 1.

At the beginning, it is the task of the user to select the design parameters, the process parameters and the part build orientations with their technically feasible limits. While the limits for the process parameters are defined by the selected printer, the product developer defines the limits for the design parameters with respect to the freedom in design. The subsequent build time sensitivity analysis is done completely automated (see Figure 2).

Therefore, a virtual design of experiments is devised by a suitable sampling method to consider the possible variations of the input parameters. Using the Monte Carlo Simulation, it is possible to reduce the number of required samples. In doing so, the different values of the independent parameters are randomly combined. It is well-known, that the choice of the sample size $n$ has a significant influence on the results. In general, the appropriate sample size always depends on the type of problem and the number of parameters to be studied. However, it can be stated on the basis of various study cases that a sample size of 10000 samples delivers reliable results in the context of build time sensitivity analysis.

In the next step, the build time is estimated for each sample $i$, using the build time estimator of a suitable slicing software with the direct and indirect input arguments. In order to consider the part build 
orientation as well as the sample values for the individual process parameters, these settings are automatically adapted and transferred to the slicer as direct input. Since the toolpaths are always generated on the basis of the CAD model, which usually has to be available in a tessellated representation form, the initial geometry is adapted to the values of the current sample. At this point, a coupling with a parametric CAD software is expedient since the geometry of the part can be adapted over the different design parameters in the CAD model. This procedure facilitates the adjustment of the geometry in comparison to the tessellated input format, whose modification is more difficult due to small information depth as well as missing feature and parameter information. After the adjustment of the parameters in the CAD model, the part model is exported in a slicer-processable format and transferred to the slicer with the previously defined process parameters. Afterwards, the slicer creates the toolpaths for the manufacturing process and generates a machine-readable code considering the current design of the sample as well as the current process parameters and the part build orientation. The generated code serves as a basis for the subsequent build time analysis, which takes place in the slicer with the aid of the so-called build time estimator integrated in the slicing software. This procedure is repeated for all $n$ samples (see Figure 2). In a further step, this information serves as input to determine the influence of the considered parameters $p$ on the output variable of the build time. The density-based sensitivity analysis method according to PLISCHKE (Plischke et al., 2013) is used due to its sampling-independent applicability. While variancebased sensitivity analyses determine the main and total effects by calculating the variance or rather standard deviation (Saltelli et al., 2008), density-based methods use the probability density function estimated by the aid of kernel density estimation methods (Plischke et al., 2013). For further information regarding the different sensitivity analyses the lecture of (Saltelli et al., 2008) is recommended. As a result, there are the influences of the individual input variables as contributors or sensitivity indices, whereby the relevance of the contributor increases with its value.

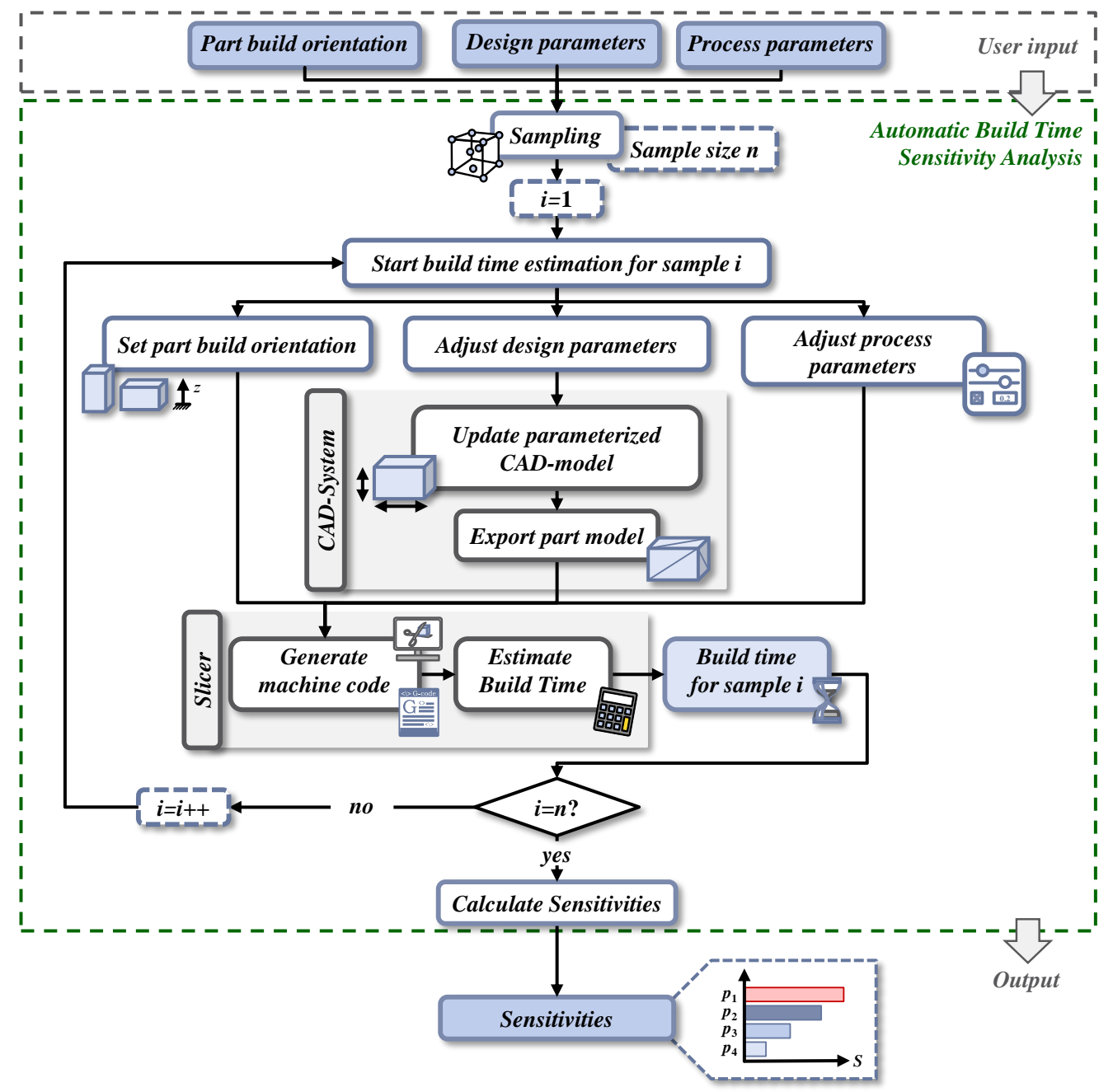

Figure 2. Detailed framework of build time sensitivity analysis method 


\subsection{Implementation}

The method presented in Figure 2 has been implemented in MATLAB R2017a using the method of density-based sensitivity analysis according to PLISCHKE (Plischke et al., 2013). For estimating the build time for FDM, the slicing software Ultimaker Cura v3.3.1.6 is used by running the CuraEngine in batch mode. Since the method is based on the toolpaths generated by the process-specific slicing software, it can easily be adapted to any other additive manufacturing process. In addition to the settings of the various process parameters the slicer also needs the CAD model in STL-, AMF- or OBJ-format. As it is already known from section 2.2, it makes sense to integrate a parametric CAD system in the process of the build time sensitivity analysis (see Figure 2). In this contribution, PTC Creo ${ }^{\circledR}$ Parametric 4.0 is used in batch mode for an automatic generation of the various variants according to the current sampling. Thus, only the CAD model parameterized according to the design parameters as well as the relevant process parameters with the respective limits have to be transferred as input for the automated build time sensitivity analysis. As a result, the contributor of each individual influencing parameter to the build time is known while taking the current product and a specific machine into account.

\section{APPLICATION}

In the following, the method presented in section 2 is exemplarily applied to a case study. After presenting the component to be additively manufactured in section 3.1, the contributors of selected design and process parameters are estimated in section 3.2 for a given Fused Deposition Modeling printer and are discussed in section 3.3 .

\subsection{Presentation of the case study}

Unmanned flying objects arouse interest not only for leisure activities, but also in industry, for example for transport or surveillance purposes. In this case study, the influence of the design of the frame of a quadrocopter in combination with the process parameters is studied. The frame of the quadrocopter consists of four arms for each rotor, as it is illustrated in Figure 3.

a)

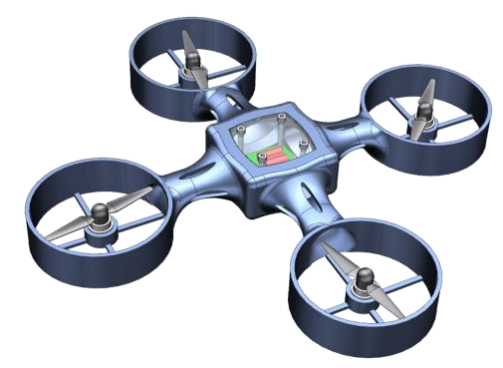

b)

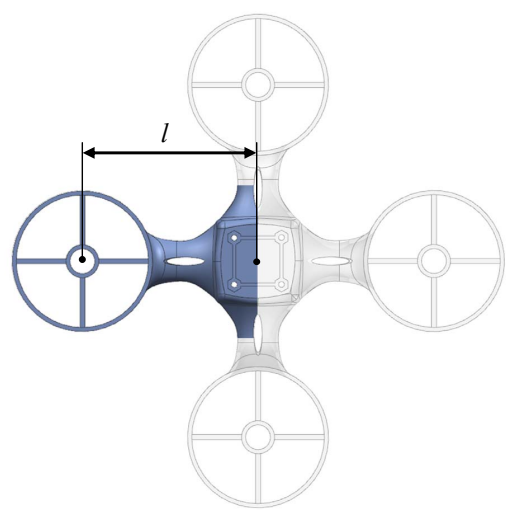

c)

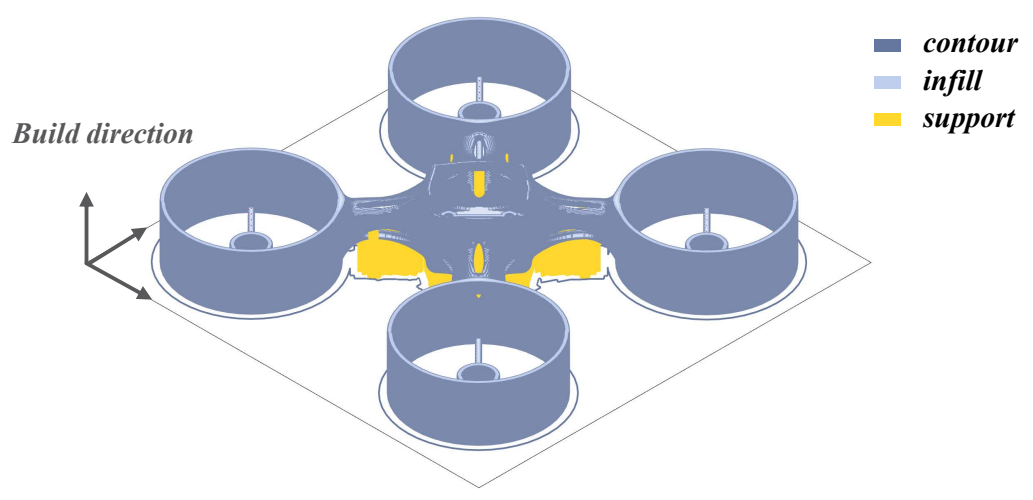

Figure 3. Additively manufactured frame of a drone: a) Assembly of the drone, b) Design parameter to be studied, c) Visualization of sliced part model 
The frame is designed in a so-called ' $\mathrm{x}$-configuration', meaning that the arms are arranged in $\mathrm{x}$-shape. Besides the mounting of the electronic and driving elements, the frame functions as the housing of the drone. In the following, the influence of the distance between the center of the rotors and the center of gravity of the drone is exemplarily studied. Therefore, the length $l$ of the arm with a variation between $100 \mathrm{~mm}$ and $115 \mathrm{~mm}$, which is equal for each of the four rotors, is set as design parameter to be analyzed (see Figure 3b)).

\subsection{Build time sensitivity analysis of a drone frame}

Besides the design with its parameter presented in section 3.1, the process parameters have to be defined as input for the build time sensitivity analysis method (see Figure 2). Thus, the process parameters, which are studied in this contribution, are summarized in Figure 4.

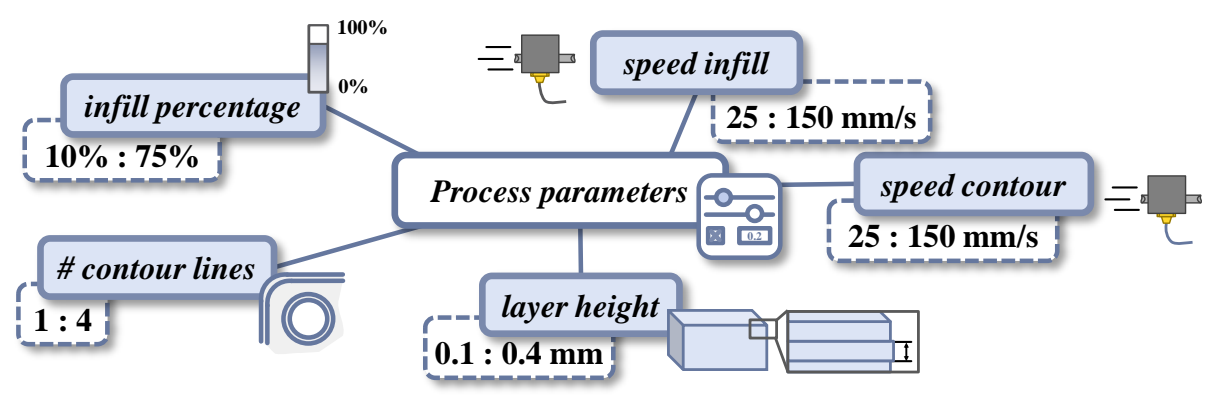

Figure 4. Selection of process parameters to be studied in the case study

Besides the layer height, the number of contour lines, the level of infill and the manufacturing speed of the contour and the infill are considered in this case study. All parameters are uniformally distributed, the limits are specified in Figure 4. Since the frame is a flat, large-area component, only the part build orientation with a flat support, as it is illustrated in Figure $3 \mathrm{c}$ ), is practical. For this reason, the influence of the part build orientation is not considered in this study. Furthermore, the number of samples with $n=10000$ was determined on the basis of previous studies to be sufficiently large to produce valid results in reasonable computation times.

\subsection{Results and discussion}

After defining the design via a parametrized CAD model of the frame by setting the length of the arms as design parameter with its limits and setting all parameters according to Figure 4, the sensitivity analysis for the sample size $n$ is performed automatically. The resulting contributors are represented in a bar chart in Figure 5.

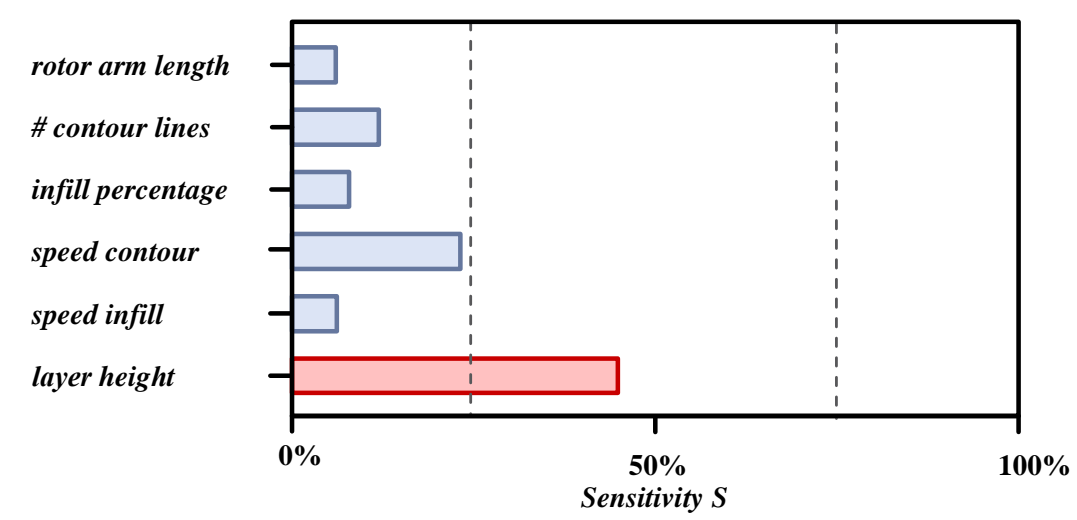

Figure 5. Resulting sensitivities of the influence parameters for the given case study 
It can be claimed that the layer height has the greatest influence on the required build time. This seems plausible because halving the layer height, for instance, will roughly double the build time. Therefore, it makes sense to select the layer height only as low as necessary, but as high as possible for the respective application. To reduce the build time, adaptive slicing has also become established, which allows the layer thickness to be differently defined for individual sections along the build direction (Tata et al., 1998). By individually adjusting the layer height above the part height, the product developer can achieve a good quality at specified part locations while keeping the build time low. Furthermore, it can be seen that the speed of the contour and the number of contour lines have a greater impact on the resulting build time than the infill percentage and the speed to create the infill. At this point this is also plausible because the frame is designed as a closure with small cross-sectional areas. This way, the adjustment of the settings affecting the contours has a stronger effect than the settings for controlling the filling of the part. For components with larger cross-sectional areas a shift of the contributions of infill and contour is expected. An adaption of the design by adjusting the rotor arm length within the given limits has a relatively small influence. However, it has to be noticed that this depends on the respective design, its design parameters and limits.

\section{CONCLUSION AND OUTLOOK}

Additive manufacturing processes have made the leap into industrial production, but are often not consequently used due to long build times. A carefully targeted adjustment of the process and design parameters can significantly reduce the build time and thus makes the process more applicable. The definition of the geometry already determines the build time and thus also the influences of the different manufacturing parameters. However, existing methods either are limited to only a few parameters or are not easy to use for product developers, who usually have limited manufacturing knowledge. As a consequence, the analysis of the influences on the build time from both the production and design point of view is not supported yet.

In order to close this research gap, this paper introduced a novel method for build time sensitivity analysis. By integrating a suitable CAD-system and slicer software, the product developer can identify the main contributors on the build time taking the current geometry into account. This information is very useful to understand the manufacturing process in combination with the design and supports the product developer by defining a process-orientated design of additively manufactured components. The exemplary application to a case study manufactured by Fused Deposition Modeling has demonstrated its suitability and applicability and showed first correlations between process and design parameters and the resulting build time. However, since the variation of process and design parameters not only affects build time but also the product quality, e.g. component accuracy and surface quality, the product developer must always find a compromise in the conflict between build time and component quality. In order to take the effects of the process parameters on component quality into account, the presented method can also be used in combination with process simulations or suitable surrogate models mapping the experimentally investigated manufacturing knowledge. This information can serve as a basis for a multicriterial optimization process for the additive manufacturing of products in as low as possible build times while still maintaining the required component quality.

\section{REFERENCES}

Ali, F., Chwodary, B.V. and Maharaji, J. (2014), "Influence of Some Process Parameters on Build Time, Material Consumption, and Surface Roughness of FDM Processed Parts: Inferences Based on the Taguchi Design of Experiments", The 2014 IAJC/ISAM Joint International Conference, Orlando, 25.09-27.09.2014.

Baumers, M., Wildman, R., Tuck, C., Dickens, P. and Hague, R. (2015), "Modeling build time, process energy consumption and cost of jetting-based Additive Manufacturing", NIP \& Digital Fabrication Conference, Vol. 2015 No. 1, January 2015, pp. 311-316.

Chen, C.C. and Sullivan, P.A. (1996), "Predicting total build-time and the resultant cure depth of the 3D stereolithography process", Rapid Prototyping Journal, Vol. 2 No. 4, pp. 27-40. http://doi.org/10.1108/13552549610153389.

Choi, S.H. and Samavedam, S. (2002), "Modelling and optimisation of Rapid Prototyping", Computers in Industry, Vol. 47 No. 1, pp. 39-53. http://doi.org/10.1016/S0166-3615(01)00140-3. 
Di Angelo, L. and Di Stefano, P. (2011), “A neural network-based build time estimator for layer manufactured objects", The International Journal of Advanced Manufacturing Technology, Vol. 57 No. 1-4, pp. 215-224. http://doi.org/10.1007/s00170-011-3284-8.

Durgun, I. and Ertan, R. (2014), "Experimental investigation of FDM process for improvement of mechanical properties and production cost”, Rapid Prototyping Journal, Vol. 20 No. 3, pp. 228-235. http://doi.org/10.1108/RPJ-10-2012-0091.

Frank, D. and Fadel, G. (1995), "Expert system-based selection of the preferred direction of build for rapid prototyping processes", Journal of Intelligent Manufacturing, Vol. 6 No. 5, pp. 339-345. http://doi.org/10.1007/BF00124677.

Griffiths, C.A., Howarth, J., Rowbotham, G.d.-A. and Rees, A. (2016), "Effect of build parameters on processing efficiency and material performance in fused deposition modelling", Procedia CIRP, Vol. 49, pp. 28 -32. http://doi.org/10.1016/j.procir.2015.07.024.

Hallmann, M., Spruegel, T., Kelber, V., Schleich, B. and Wartzack, S. (2018), "Steigerung der Bauteilqualität durch Erhöhung der Anlagensteifigkeit eines FDM-Druckers”, Konstruktion, Vol. 70 No. 7/8, pp. 73-76.

Hallmann, M., Kunz, D., Schleich, B. and Wartzack, S. (2018), “Analyse anlagenspezifischer Fertigungseinflüsse auf die Genauigkeit FDM-gedruckter Bauteile”, in Krause, D., Petzold, K., Wartzack. S. (Eds.), Design for X - Beiträge zum 29. DfX Symposium, TuTech Verlag, Hamburg, pp. 167-178.

Han, W., Jafari, M.A. and Seyed, K. (2003), "Process speeding up via deposition planning in fused deposition-based layered manufacturing processes", Rapid Prototyping Journal, Vol. 9 No. 4, pp. $212-218$. http://doi.org/10.1108/13552540310489596.

Ingole, D.S., Deshmukh, T.R., Kuthe, A.M. and Ashtankar, K.M. (2011), "Build orientation analysis for minimum cost determination in FDM", Proceedings of the Institution of Mechanical Engineers, Part B: Journal of Engineering Manufacture, Vol. 225 No. 10, pp. 1925-1938. http://doi.org/10.1177/0954405411413694.

Kechagias, J., Anagnostopoulos, V., Zervos, S. and Chryssolouris, G. (1997), "Estimation of build times in Rapid Prototyping Processes", in Dickens, P.M. (Ed.), Proceedings of the 6th European Conference on Rapid Prototyping \& Manufacturing, University of Nottingham, Nottingham, pp. 137-148.

Komineas, G., Foteinopoulos, P., Papacharalampopoulos, A. and Stavropoulos, P. (2018), "Build Time Estimation Models in Thermal Extrusion Additive Manufacturing Processes", Procedia Manufacturing, Vol. 21, pp. 647-654. http://doi.org/10.1016/j.promfg.2018.02.167.

Kumar, G.P. and Regalla, S.P. (2011), "Optimization of Support Material and Build Time in Fused Deposition Modeling (FDM)", Applied Mechanics and Materials, Vol. 110-116, pp. 2245-2251. http://doi.org/10.4028/www.scientific.net/AMM.110-116.2245.

Luft, T., Le Cardinal, J. and Wartzack, S. (2016), "Methoden der Entscheidungsfindung”, in Lindemann, U. (Ed.), Handbuch Produktentwicklung, Carl Hanser Verlag GmbH \& Co. KG, München, pp. 759-804.

Mohamed, O.A., Masood, S.H. and Bhowmik, J.L. (2015), “Optimization of fused deposition modeling process parameters. A review of current research and future prospects", Advances in Manufacturing, Vol. 3 No. 1, pp. 42-53. http://doi.org/10.1007/s40436-014-0097-7.

Munguía, J., Ciurana, J. and Riba, C. (2009), "Neural-network-based model for build-time estimation in selective laser sintering”, Proceedings of the Institution of Mechanical Engineers, Part B: Journal of Engineering Manufacture, Vol. 223 No. 8, pp. 995-1003. http://doi.org/10.1243/09544054JEM1324.

Nancharaiah, T. (2011), "Optimization of Process Parameters in FDM Process Using Design of Experiments", International Journal on Emerging Technologies, Vol. 1 No. 2, pp. 100-102.

Oh, Y. and Behdad, S. (2016), "Assembly Based Part Design to Improve the Additive Manufacturing Productivity. Process Time, Cost and Surface Roughness", Proceedings of the ASME 2016 International Design Engineering Technical Conferences \&Computers and Information in Engineering Conference Charlotte, 21.08-24.08.2016, ASME, http://doi.org/10.1115/DETC2016-59652.

Peng, A., Xiao, X. and Yue, R. (2014), "Process parameter optimization for fused deposition modeling using response surface methodology combined with fuzzy inference system”, The International Journal of Advanced Manufacturing Technology, Vol. 73 No. 1-4, pp. 87-100. http://doi.org/10.1007/s00170-014-5796-5.

Plischke, E., Borgonovo, E. and Smith, C.L. (2013), “Global sensitivity measures from given data”, European Journal of Operational Research, Vol. 226, pp. 536-550. http://dx.doi.org/10.1016/j.ejor.2012.11.047.

Pradel, P., Bibb, R., Zhu, Z. and Moultrie, J. (2018), "Exploring the Impact of Shape Complexity on Build Time for Material Extrusion and Material Jetting”, in Meboldt, M. and Klahn, C. (Eds.), Industrializing Additive Manufacturing - Proceedings of Additive Manufacturing in Products and Applications - AMPA2017, Springer International Publishing, Cham, pp. 24-33. http://doi.org/10.1007/978-3-319-66866-6_3. 
Rao, R.V. and Rai, D.P. (2016), “Optimization of fused deposition modeling process using teaching-learning-based optimization algorithm”, Engineering Science and Technology, an International Journal, Vol. 19 No. 1, pp. 587-603. http://doi.org/10.1016/j.jestch.2015.09.008.

Rayegani, F. and Onwubolu, G.C. (2014), "Fused deposition modelling (FDM) process parameter prediction and optimization using group method for data handling (GMDH) and differential evolution (DE)", The International Journal of Advanced Manufacturing Technology, Vol. 73 No. 1-4, pp. 509-519. http://doi.org/10.1007/s00170-014-5835-2.

Saltelli, A., Ratto, M., Andres, T., Campolongo, F., Cariboni, J., Gatelli, D., Saisana, M. and Tarantola, S. (2008), Global Sensitivity Analysis: The Primer, John Wiley \& Sons, New York. http://doi.org/10.1002/9780470725184.

Sanati-Nezhad, A., Vatani, M., Barazandeh, F. and Rahimi, A.R. (2009), "Determining the optimal build directions in layered manufacturing", WSEAS TRANSACTIONS on APPLIED and THEORETICAL MECHANICS, Vol. 4 No. 4, pp. 185-194.

Srivastava M., Maheshwari, S. and Kundra T.K. (2015), "Optimization of Build Time and Model Volume for A FDM Maxum Modeler Using Response Surface Methodology", International Journal For Technological Research In Engineering, Vol. 2 No. 7, pp. 1050-1057.

Tata, K., Fadel, G., Bagchi, A. and Aziz, N.(1998), "Efficient slicing for layered manufacturing”, Rapid Prototyping Journal, Vol. 4 No. 4, pp. 151-167. https://doi.org/10.1108/13552549810239003.

Thrimurthulu, K., Pandey, P.M. and Venkata Reddy, N. (2004), "Optimum part deposition orientation in fused deposition modeling”, International Journal of Machine Tools and Manufacture, Vol. 44 No. 6, pp. 585-594. http://doi.org/10.1016/j.ijmachtools.2003.12.004.

Wohlers, T.T., Campbell, I. (2017), Wohlers report 2017: 3D printing and additive manufacturing state of the industry annual worldwide progress report, Wohlers Associates Inc., Fort Collins.

Zhu, Z., Dhokia, V. and Newman, S.T. (2016), "A new algorithm for build time estimation for fused filament fabrication technologies", Proceedings of the Institution of Mechanical Engineers, Part B: Journal of Engineering Manufacture, Vol. 230 No. 12, pp. 2214-2228. http://doi.org/10.1177/0954405416640661.

Ziemian, C.W. and Crawn III, P.M. (2001), "Computer aided decision support for fused deposition modeling", Rapid Prototyping Journal, Vol. 7 No. 3, pp. 138-147. http://doi.org/10.1108/13552540110395538.

\section{ACKNOWLEDGMENTS}

The authors thank the German Research Foundation (DFG) for supporting the research project "Statistical tolerance analysis of linkage mechanisms taking into account deviations from additive manufacturing" under the grant number WA 2913/27-1. 